\title{
Femicidio y emociones en la Argentina rosista: el caso de Paulino Rojas y Encarnación Fierro.
}

\author{
Vanesa Miseres \\ University of Notre Dame (Indiana, EE.UU.)
}

\section{Resumen}

La violencia de género y el femicidio conforman el centro de los debates actuales en torno al feminismo y han sido, sin duda, uno de los principales ejes de movilización pública y política en la última década en la Argentina y en el resto de Latinoamérica. Este artículo propone una mirada histórica sobre el tratamiento y la visibilidad social de ambos términos (violencia de género y femicidio) a partir del estudio de un caso particular del siglo XIX argentino: el del militar Paulino Rojas, integrante del Regimiento de Granaderos a Caballo y partícipe de la campaña libertadora del Perú, y el juicio al que se lo sometiera por ser el principal sospechoso de la muerte de su esposa, Encarnación Fierro. El caso de Rojas y Fierro es un ejemplo clave para entender las relaciones, jerarquías y alianzas interpersonales (militares, amorosas, familiares, de amistad) del período rosista, el valor de las emociones en la construcción de los sujetos en el siglo XIX y el impacto de las mismas en el ejercicio de la ciudadanía y los derechos, aún en pugna, de las mujeres.

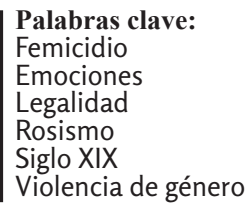

\begin{abstract}
Gender violence and femicide are in the center of current debates about feminism and have undoubtedly been one of the main axes of public and political mobilization in the last decade in Argentina and the rest of Latin America. This article proposes a historical view on the treatment and social visibility of both terms (gender violence and femicide) from the study of a particular case of $19^{\text {th }}$ century Argentina: the trial of military and independence hero Paulino Rojas, the main suspect in the death of his wife, Encarnación Fierro. The case of Rojas and Fierro
\end{abstract}

1 Agradezco la enorme colaboración de Norma Alloatti en el proceso de investigación y búsqueda de fuentes para la escritura de este trabajo. 
is a key example to understand the relationships, hierarchies, and interpersonal alliances (military and affective) of the Rosista period, the value of emotions in the construction of subjects in the $19^{\text {th }}$ century, and their impact on citizenship and women's rights.

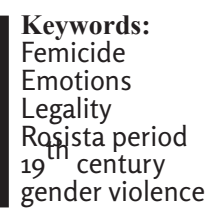

La violencia de género y el femicidio conforman el centro de los debates actuales en torno al feminismo y han sido, sin duda, uno de los principales ejes de movilización pública y política en la última década en la Argentina y en el resto de Latinoamérica. ${ }^{2}$ Este artículo propone una mirada histórica sobre el tratamiento y la visibilidad social de ambos términos (violencia de género y femicidio) a partir del estudio de un caso particular del siglo XIX argentino: el del militar Paulino Rojas, integrante del Regimiento de Granaderos a Caballo y partícipe de la campaña libertadora del Perú, y el juicio al que se lo sometiera por ser el principal sospechoso de la muerte de su esposa, Encarnación Fierro. Dicho juicio, cuya publicación estuvo a cargo de Manuel Belgrano (sobrino del prócer nacional), además de garantizarle al abogado defensor de Rojas, Valentín Alsina, el éxito en su carrera legal, nos sirve hoy en día como testimonio clave del modo en que se abordaba la violencia contra la mujer en el período rosista.

Tomando como eje algunas conceptualizaciones teóricas sobre el papel social y legal de las emociones (Nussbaum, 2006; Peluffo, 2016, entre otrxs), mi lectura sobre el juicio a Rojas se detendrá particularmente en el análisis de los argumentos utilizados tanto en la defensa de Alsina como en las acusaciones contra Rojas para proponer un "giro afectivo" (Clough y Halley, 2007) en el estudio de la Argentina rosista y los roles de género vigentes en el período. Más allá de los estatutos legales, el debate sobre la culpabilidad o la inocencia de Rojas parte del plano emocional y de la percepción social de los afectos. Defensores y acusadores del militar someten a escrutinio público los desvíos amorosos, las pasiones y las emociones desmedidas de la víctima y, a favor o en contra del acusado, sitúan la muerte de Encarnación Fierro en un ideal de amor romántico que se trunca presuntamente a causa de los celos de un hombre que, en última instancia, busca defender su honor y reputación en el panteón de los héroes nacionales. El juicio culmina con la pena del destierro de Rojas por ocho años fuera de la provincia de Buenos Aires y la siguiente absolución dictada por Juan Manuel de Rosas, en retribución al militar por sus hazañas heroicas al servicio de la patria. En un país en el que hasta hace poco tiempo el femicidio era categorizado como "crimen pasional", vale la pena reflexionar históricamente sobre los orígenes de las asociaciones entre emoción, política y legalidad. El caso de Rojas y Fierro es un ejemplo clave para entender las relaciones, jerarquías y alianzas interpersonales (militares, amorosas, familiares, de amistad) del período rosista, el valor de las emociones en la construcción de los sujetos en el siglo XIX y el impacto de las mismas en el ejercicio de la ciudadanía y los derechos, aún en pugna, de las mujeres.

2 El término femicidio o feminicidio en español proviene de "femicide", formulado en inglés en 1974 por la escritora estadounidense Carol Orlock, aunque lo comenzó a usar públicamente la feminista Diana Russell a partir de 1976. Para una conceptualización e historia del término, ver los trabajos de Ana María Fernández (2012: 47-73) y Jorge Buompadre (2013). 


\section{Emociones, género y legalidad en el siglo XIX}

Siguiendo lo propuesto por Sarah Ahmed en The Cultural Politics of Emotions (2015), un breve repaso por los principales discursos (literarios, religiosos, pedagógicos, legales y médicos) nos lleva a sostener que el mundo de las emociones en el siglo XIX latinoamericano no refleja un estado psicológico interior, sino que se trata de prácticas sociales y culturales cuidadosamente reguladas. Al momento de definir la matriz que caracteriza una época, Max Weber (1993) ya había introducido la idea de "comunidades afectivas" y Raymond Williams se refería a las "estructuras de sentimiento" (1977: 150) para aludir a una especie de estado de ánimo de una sociedad en un período histórico determinado que, por un lado, da forma a la cultura y, por el otro, permite explorar zonas excluidas del paradigma racionalista. Carol Gilligan (1993), Chantal Mouffe (2000) y Martha Nussbaum (2006), entre otrxs, han profundizado sobre este aspecto y cuestionado las jerarquías de la dicotomía razones/emociones, la cual, a la hora de validar conocimientos, ha servido históricamente para privilegiar a la primera, entendida la razón también de manera fija y aislada. Para Nussbaum, puntualmente, las emociones son formas de pensamiento y conocimiento.

En el siglo XIX, esas estructuras colectivas de sentimiento estuvieron marcadas, a su vez, por las diferencias genéricas entendidas de forma binaria. Es decir, los grupos de emociones se distinguían entre aquellos que debían o podían sentir los hombres y las mujeres, y por los modos en que estas emociones o sentimientos (no hago una diferenciación entre los términos en este estudio) podían ser expresados socialmente. Manuales de ciudadanía, tratados médicos y obras literarias y filosóficas ubicaban a las mujeres como sujetos emocionales y, en consecuencia, carentes de racionalidad. El mismo corpus textual fue determinando así también los modos diferenciales de expresar las emociones en público y programando a las mujeres hacia un comportamiento más pasivo que el de los hombres, por ejemplo, a través de las lágrimas que Ana Peluffo estudia en el contexto andino. ${ }^{3}$ A finales del siglo XVIII y principios del XIX, sostiene Leidy Bolaños Florido, "la liberación indisciplinada de los sentimientos como atributo femenino tuvo su correlato en el autocontrol de los impulsos como cualidad asociada a la construcción de la masculinidad" (2016: 180) y al buen funcionamiento de la sociedad moderna en general.

Desde la filosofía antigua y bajo diversas concepciones de las emociones a lo largo de la historia occidental, se hizo constante la necesidad de cultivar, medir o educar las emociones con el fin de crear un individuo virtuoso y promover una vida social que privilegie la razón (masculina) por sobre la emoción (femenina) (Camps, 2011). Este ideal masculino de autocontrol cobra un nuevo sentido en el contexto del reformismo ilustrado y de su apuesta por la transformación moral de los individuos como condición necesaria para la reforma de la nación (Bolufer, 2007: 7-31). En En clave emocional: cultura y afecto en América Latina, Peluffo reconstruye la historia cultural de los afectos en Latinoamérica y, considerando las modulaciones locales de las emociones en la literatura y culturas del continente, confirma asimismo la centralidad de las mismas en la constitución "afectiva" de las naciones (2016: 16). Para Peluffo, la clásica oposición entre civilización y barbarie puede entenderse desde una lectura de las emociones: mientras que algunas como odio, rabia o indignación (de acuerdo con la clasificación de Norbert Elias) se consideran bárbaras, otras emociones de autocontrol (asco, vergüenza, pudor) representan al ciudadano (otra vez masculino) modelo de las nacientes repúblicas (2016: 19).

3 En Lágrimas andinas... (2005), Peluffo analiza el uso de la retórica sentimental por parte de Clorinda Matto de Turner como un mecanismo didáctico y una estrategia para comunicar sus ideas sobre el género y el indigenismo en un contexto social y literario peruano que, de otra forma, le habría sido negado. 
Lauren Berlant, por su parte, en El corazón de la nación, sostiene que los afectos son elementos clave a la hora de evaluar la política pero, así como en algunos casos pueden devenir en transformadores, en otros no hacen más que refrendar el statu quo (2011). Esta última afirmación explica la situación de las mujeres, cuyas emociones "desmedidas" fueron una justificación para continuar con su sumisión social y legal a lo largo de un siglo en pleno proceso de cambios. Mónica Bolufer, por su parte, analiza cómo la ciencia y la religión contribuyeron en la Edad Media a perpetuar y naturalizar las diferencias de género apelando a las emociones femeninas, de acuerdo con la teoría de los humores, la misma que puede verificarse como antecedente de muchos de los discursos sobre el comportamiento y naturaleza femeninos siglos más tarde. La teoría de los humores establecía, también, claras diferencias de acuerdo con el género: los hombres y las mujeres poseían distintos grados de cualidades básicas como frío, calor, sequedad o humedad (2009: 87). El calor y la sequedad del temperamento masculino representaban las condiciones más propicias para el conocimiento, que marginaba entonces a la mujer, usualmente asociada a lo húmedo y al frío. Estas formas de entender las diferencias de género, explica Bolufer, no se restringieron a la medicina, sino que prevalecieron en la cultura y pensamiento populares de la época, siendo los ejes de los debates filosóficos y literarios sobre la naturaleza (inferior y perniciosa) de las mujeres (querella de mujeres) y, como veremos más adelante, sobre el matrimonio hasta bien entrado el siglo XVIII. Por ejemplo, como individuos secos y calientes, a los hombres se les permitía tener arranques de rabia y agresión, mientras que el frío y la humedad de las mujeres les permitía alojar pasiones por largo tiempo que resultaban en su propio detrimento y en el de los demás (Frevert, 2011). De esta manera, a la hora de apelar una sentencia, una mujer que hubiera matado a su marido utilizaría argumentos diferentes al de un hombre que hubiera asesinado a su esposa. Mientras el hombre podía excusarse en la rabia, las mujeres preferían utilizar la angustia y la desesperación, ya que la expresión de la ira no les era permitida (Frevert, 2011).

En la literatura occidental, Jean-Jacques Rousseau fue una de las figuras principales en promover un modelo de ciudadano idealizado con obras como Julia, o la nueva Eloísa (1761) y Emilio, o de la educación (1763). Ambos textos no solo proyectan la imagen de un protagonista virtuoso y armónico en la expresión de sus emociones, sino que dejan también en claro (sobre todo en Emilio) que dicho ideal excluye a las mujeres, quienes deben limitarse a la delicadeza y la docilidad. ${ }^{4}$ En la tradición literaria de nuestro continente, contamos con novelas como María (1864-1867) de Jorge Isaacs, Amalia (1851-1852/1855) de José Mármol, o Aves sin nido (1889) de Clorinda Matto de Turner que continúan con este modelo presentando personajes femeninos cuya agencia se formula siempre desde la pasividad emocional y medida, expresada muchas veces por las mencionadas lágrimas, impuestas culturalmente para su género.

Dentro del plano legal, como se anticipó, las emociones y su clasificación genérica sirvieron igualmente para regular la vida matrimonial. La ley es reflejo de los valores y creencias de las sociedades en las que se crea y opera, de manera tal que debemos entenderla como una narrativa que es simultáneamente legal, cultural y emocional (Barclay, 2017: 206). Sobre el siglo XIX chileno, Verónica Undurraga Schüler afirma que las emociones, al igual que en los siglos anteriores, se utilizaron como argumento de los pleitos conyugales, dentro de los que - tal como veremos en adelante en el caso de Paulino Rojas- el descontrol asociado a la impulsividad de las emociones se presentaba como explicación de gran parte de las disputas y como justificación de la violencia masculina (2016). Las argumentaciones judiciales, por otra parte, conformaron, junto con la correspondencia, una de las vías

4 Estos dos ejemplos de Rousseau son también analizados por Bolufer en “'Hombres de bien': modelos de masculinidad y expectativas femeninas, entre la ficción y la realidad” (2007). 
privilegiadas para el acceso a las emociones de las mujeres decimonónicas, siendo las primeras, además, una comprobación de que la teoría humoral seguía vigente como parámetro evaluador, junto con un modelo científico-filosófico que fundía las teorías darwinistas con el positivismo: "La cólera y la melancolía femeninas fueron los humores más utilizados para explicar los conflictos conyugales y, a su vez, para justificar la 'corrección' o el castigo 'legítimo' del esposo sobre el cuerpo de la "mujer colérica"' (Undurraga Schüler, 2016:408).

En la Argentina, el matrimonio fue regido por la norma colonial hasta 1852 . Tal como lo expresa Dora Barrancos, "la familia fue especialmente puesta en foco, un ancla que aseguraba el organismo social" (2010: 101). Por este motivo, pese a las nuevas regulaciones, el hombre fue quien mantuvo el control sobre la mujer. Tanto el código napoleónico de 1804, adoptado por la mayoría de los países latinoamericanos en proceso de independencia, como el posterior código de Dalmacio Vélez Sársfield de 1869 , trajeron escasos cambios a la situación de las mujeres. La familia autoritaria y patriarcal fue la figura dominante para las relaciones sociales y los códigos continuaron con el derecho castellano-indiano en materia de familia (Fernández Rozas, 2005: 151-190; Mira, 2018). Bajo el código civil de Vélez Sársfield, por ejemplo, la mujer casada poseía una incapacidad relativa (artículo 55) y a todos sus efectos su representante era el marido, dejándola sin derecho a la educación ni a realizar actividades comerciales sin su consentimiento (artículo 57) (Barrancos, 2010). Cotejado este código con el derecho punitivo, sostiene Barrancos, se puede comprender la solidez de la discriminación de género, ya que la norma establecía diferentes parámetros de acuerdo con el género para delitos como el adulterio, uno de los argumentos que empleará Valentín Alsina en defensa de Paulino Rojas.

Mientras que el asesinato a la esposa sorprendida en una situación de adulterio era considerado un atenuante para el hombre, matar al marido era un agravante para la mujer "debido justamente al vínculo" (Barrancos, 2010: 103). Como veremos también más adelante, el concepto hispánico del honor - de fuerte raíz afectiva - fue reforzado en el sistema legal americano que, pese a la argumentada modernidad de sus normas, siguió sosteniéndose sobre y perpetuando las estructuras patriarcales y un modelo de ciudadanía basado en la virilidad masculina que debía asegurarse en cualquier condición social. Como denuncia la escritora Juana Manso en su ensayo "Emancipación moral de la mujer" sobre las leyes dispuestas y formuladas por los hombres: "lo que en ella clasifica crimen en él lo atribuye a debilidad humana" (2010 [1854]: s/p).

Puntualmente durante el rosismo, y en el período que va de 1829 a 1832, Juan Manuel de Rosas gobernó con facultades excepcionales otorgadas por la Legislatura al Poder Ejecutivo durante la querra civil promovida por Lavalle, por Ley del 6 de diciembre de 1829 (Carmona y Fernández, 1999: 203). Esto hizo que el gobernador tuviera la potestad judicial del Poder Ejecutivo, a pesar de que legisladores y magistrados continuaron en sus funciones. Julieta Mira establece que la instrumentación de penas y castigos se llevó a cabo "careciendo de un sistema organizado y homogéneo, con severidad y ausencia de plena igualdad y proporcionalidad" (2018: 174). En la misma línea argumental, Ricardo Salvatore hace referencia a una "justicia dual" que combinaba formas antiguas y modernas: por un lado, se le daba poder de decisión a los jueces de paz locales y, por el otro, existía un sistema judicial central que podía operar también sobre los casos (1994: 100). La falta de códigos penales y correccionales impedía una separación clara entre delito, contravención y otros tipos de ilegalidades y permitía cierta flexibilidad en las normas (Salvatore, 1994). Así, en el derecho patrio, explica Abelardo Levaggi, la independencia política no implicó necesariamente el establecimiento de un sistema jurídico independiente, de 
manera que el legado colonial del derecho penal indiano también estaba presente durante el rosismo (Levaggi, 2012; Olaza Pallero, 2016).

Llamado en su tiempo "el restaurador de las leyes", a Rosas le preocupaba la aplicación del dispositivo legal entre lxs gobernadxs, aun cuando este estuviera compuesto de un conjunto confuso de leyes, decretos, circulares y notas sobre los más diversos aspectos del gobierno y la policía de la campaña. Muchas de esas normativas buscaban regular y construir "comunidades afectivas" sobre el ya mencionado ideal moderno y civilizatorio. Por ejemplo, se propone un control minucioso de la vida pública y de las costumbres de los pueblos, estableciendo claros mandatos sobre el comportamiento en eventos como bautismos, sepelios, juegos, reuniones públicas o festividades religiosas: la prohibición de portar cuchillos y de los juegos de carnaval son solo dos ejemplos de esta inquietud (Salvatore, 1994: 96).

Respecto a lo que hoy denominamos "violencia de género" y a través de los archivos judiciales disponibles, Salvatore afirma que las agresiones contra las mujeres adquirieron mayor visibilidad, ya que muchas se resistieron al ideal patriarcal y a la norma legal de la "corrección" o "castigo" a su género por parte de sus esposos o empleadores y se animaron a denunciar muchos de estos maltratos y abusos. Entre las vejaciones más comunes que fueron denunciadas, el autor destaca los raptos de mujeres jóvenes, las violaciones, el estupro y, sobre todo, la violencia física de hombres hacia esposas e hijas (1994: 104-105). En general, las denuncias reciben castigos, pero, nuevamente, sin un criterio unificador en las condenas y reflejando el lugar menor de la mujer frente a los denunciados. Sobre el matrimonio, por otra parte, la Recopilación de las leyes y decretos promulgados en Buenos Aires, desde el 25 de mayo de 1810, hasta fin de diciembre de 1840 realizada por Pedro De Angelis, exhibe un interés particular por oficializar y llevar una estadística de las uniones que controle el origen de los contrayentes (determinar si son locales o extranjeros, su religión y su raza). Aunque la iglesia continúa oficiando las ceremonias, se exige un reporte al encargado del Registro Civil y se les pide a los párrocos cerciorarse de los antecedentes de cada parte, sobre todo, que no se trate de individuos que ya han contraído matrimonio (XLI; XLV; CLXXVIII; 452; 351). La política estatal se establece en contra del "amancebamiento" o concubinato y asume un grado menor de moralidad (sino promiscuidad) entre aquellas mujeres que se encontraran en uniones no oficializadas. Llama la atención también, dentro de este documento, un decreto de 1823 en el que se fundan los premios de la Sociedad de Beneficencia a la moral, industria y aplicación de la mujer. Dichos premios retribuían con una suma de dinero a todas aquellas que se distinguieran "por su moralidad y por la práctica de las virtudes propias de su sexo", así como también a quienes trabajaran o estudiaran "con honradez" (s/f: 462). Este es un ejemplo a través del cual podemos ver que la ley también se impone sobre el plano de los afectos y, al mismo tiempo, opera como formador de los mismos. Para la mujer, la expresión de sus emociones se cubre especialmente de un manto moral, cuya integridad es controlada por organismos públicos. Si se considera, además, que el cumplimiento del ideal de la "perfecta casada" originado en el modelo hispánico es premiado en la vida pública, su incumplimiento podía ser igualmente castigado o resultar en un trágico final para la vida de la mujer, tal como sucede con Encarnación Fierro según el relato judicial de su muerte. En palabras de Martha Nussbaum, "si las emociones implican un juicio, el juicio de esas emociones refleja las normas de una sociedad" (2006: 46, traducción mía). 


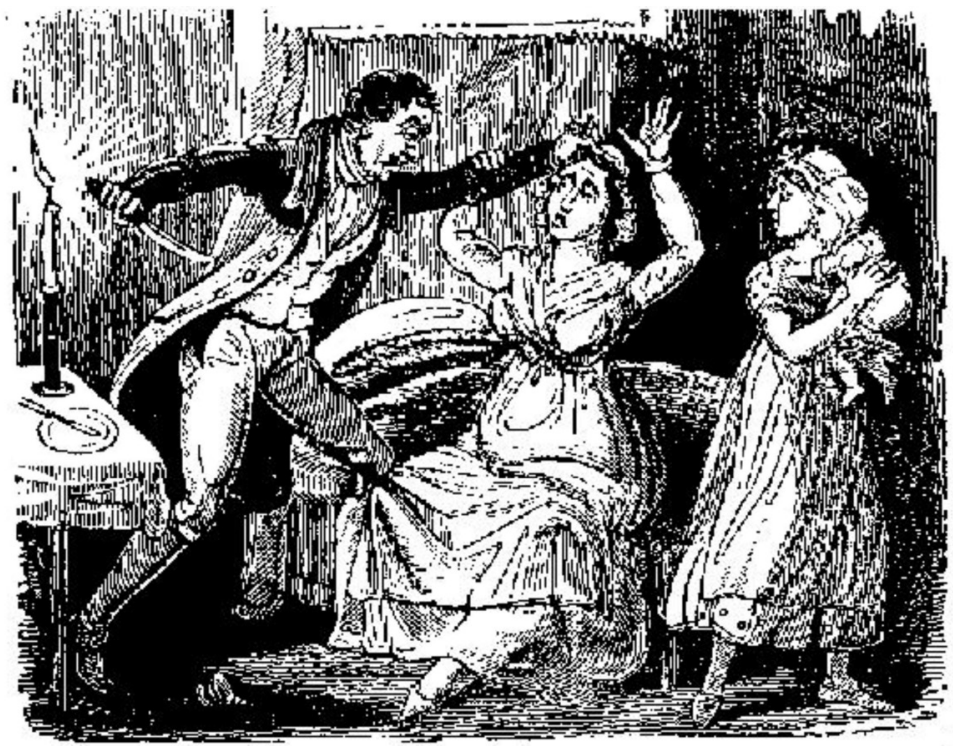

Figura 1. Ilustración del siglo XVIII. El inglés Matthias Brindsen apuñala a su esposa. Brindsen fue ejecutado el 24 de septiembre de 1722 en Inglaterra por dicho delito.

\section{El juicio por la muerte de Encarnación Fierro: entre las pasiones y el honor}

El caso de Paulino Rojas y la muerte de su esposa, Encarnación Fierro, es un claro ejemplo de la convivencia de las leyes y valores sociales coloniales con nuevos intentos de regulación institucional que, igualmente, coinciden en parámetros morales y en la percepción de los afectos de los individuos a la hora de someterlos a indagación. Paulino Rojas nació el 15 de agosto de 1796 en la ciudad de Córdoba y estudio allí mismo en el Colegio de Monserrat. A los 18 años ingresó como soldado al Regimiento de Granaderos, con el cual participó en el sitio de Montevideo, lo que le valió los galones de sargento al año siguiente y, en 1816 , los de sargento $1^{\circ}$. También se unió al Ejército de los Andes y cruzó la cordillera con José de San Martín. Después de la batalla de Chacabuco, obtuvo los despachos de alférez y, al año siguiente, ya teniente, estuvo en los combates de Cancha Rayada y Maipú. Con el grado de capitán participó también en 1820 de la expedición Libertadora al Perú, batiendo a los realistas en la Torre Blanca y en el asalto al Callao. Tras intervenir en las batallas de Junín y Ayacucho, que sellaron la independencia americana y por las cuales Simón Bolívar lo condecoró con medalla de oro, en 1825 se trasladó a Buenos Aires y participó en la Guerra con el Brasil. Allí alcanzó el grado de coronel y, de regreso a Buenos Aires por motivos de salud, fue designado comandante de Patagones y más tarde, en 1828, de la isla Martín García. Al año siguiente pasó a ocupar la comandancia de Bahía Blanca donde, se dice, mantuvo relaciones pacíficas con las comunidades indígenas de la zona. A la ciudad llegó con su esposa, Encarnación Fierro, quien era unos diez años menor que él y con la que se había casado tres años antes. El 15 de julio de 1830, recibió orden de entregarle su empleo al coronel Martiniano Rodríguez y ese mismo día se produjo la muerte de Fierro. El 6 de agosto La gaceta mercantil anunciaba que "la corbeta de guerra nacional Sarandí conduce en arresto desde la Bahía Blanca, de cuyo establecimiento era comandante, al coronel don Paulino Rojas, acusado de haber muerto el 15 de julio de un pistoletazo a su esposa doña Encarnación Fierro". ${ }^{5}$

5 Datos biográficos obtenidos del artículo "El uxoricidio de la esposa de un coronel" de La gaceta mercantil, el trabajo de Carlos José Mosso (2017: 121-163) y Tragedias de nuestra historia de Ismael Bucich Escobar. Como se verá en el análisis, estos textos citados recomponen la vida del militar en ningún caso para reflexionar sobre la temática de género y el femicidio, sino más bien, para exaltar la vida de un héroe nacional con un "desgraciado" final. 
El proceso no resultaba fácil de resolver, ya que no se encontraron testigos al momento de los hechos y los indicios podían determinar tanto un asesinato como un suicidio. No obstante, el 25 de octubre de 1831, Rojas fue condenado por la justicia en primera instancia a cinco años de presidio, contando con la defensa del entonces joven abogado Valentín Alsina. El fallo fue revocado por la Cámara de Justicia, que lo condenó a la pena de muerte, pero el mismo tribunal la conmutó por la de ocho años de destierro fuera de la Provincia de Buenos Aires (Rojas lo cumplió en Montevideo). Sin embargo, el 16 de abril de 1832, Rosas, haciendo uso de sus mencionadas facultades ordinarias y extraordinarias, lo exoneró de la pena, "con expresa declaración de que ella no le infiere en manera alguna la menor nota contra su persona, y que queda por lo mismo expedito para continuar sin mengua alguna a este respecto su brillante carrera militar" (Registro oficial, 1831: 368). En el texto de la exoneración se deja en claro el rol del gobierno de Rosas como "el primer custodio del honor del Estado" (ibídem: 366), al mismo tiempo en que se intenta sentar un caso ejemplar del trato excepcional que podrían recibir todos aquellos hombres que sirvieran al ejército. El indulto a Rojas se formula como "egemplo del singular aprecio con que deben ser mirados los servicios de todo argentino que, como el coronel D. Paulino Rojas se haya consagrado desde el principio de nuestra gloriosa revolución á sostener la causa de la independencia en el campo del honor" (ibídem: 367). De esta forma, si la masculinidad debía ser preservada como valor civil en la nación, más aún lo eran las masculinidades marciales que encarnaban en sí mismas los pilares nacionales, casi exclusivamente ligados a la guerra en la primera mitad del XIX.

ACUERDO.

Se exongra el Coronel D. Paulino Rojas

De la pena de ocho años de destierro á que há sido condenado, y se restituye al goce de su empleo.

Buenos Aires 16 de Abril de 1832.

Habiendo el Juez de 1. instancia Dr. D. Manuel Insiarte, elevado al conocimiento del Gobierno con fecha cuatro del corriente, el auto definitivo que el seis del próximo pasado Marzo, pronuncí́ en revista la Exma. Cámara de justicia de la causa criminal seguida de oficio contra el coronel de ejército $D$. Paulino Rojas, por el homicidio perpetrado en la persona de su esposa Da. Encarnacion Fierro, reformando en cuanto á la pena ordinaria de muerte, el que habia pronunciado en vista el 25 de Octubre del año anterior, á foja 142 vuelta, pieza segunda, y condenando al espresado reo á ocho años de destierro fuera de la provincia;-el Gobierno que, como

Figura 2. Primera página del decreto con el que Juan Manuel de Rosas exonera a Paulino Rojas de la pena impuesta por el asesinato de su esposa. Registro Oficial del Gobierno de Buenos Aires. Libro décimo. Imprenta de la Independencia, 1831.

El juicio a Paulino Rojas con la defensa de Valentín Alsina ocurrió durante los días 24 y 26 de agosto de 1831. En el informe se incluyen los argumentos esgrimidos por el abogado en favor de la hipótesis de suicidio de Encarnación Fierro. Resulta interesante, 
como se anticipó, que tanto la acusación como la defensa utilizaron el supuesto adulterio de Fierro como motivo disparador de su muerte: o Rojas actuó enceguecido por los celos y asesinó a su esposa, o esta se suicidó al no soportar más el tedio de su matrimonio y estar imposibilitada de vivir sus amoríos extramaritales tras la noticia de su vuelta a Buenos Aires. Como estrategia retórica, Alsina comenzó arguyendo "en contra" del defendido, detallando las presunciones a favor de la teoría del homicidio, con el fin de desmontar una por una las presunciones de la parte acusadora. El primer motivo que utilizó fue la "diferencia de sexos y carácter" (Belgrano, 1831: 26) para explicar lo razonable que resultaría acusar a Rojas de homicidio frente a una mujer, por naturaleza débil de carácter e incapaz, por eso mismo, de cometer suicidio. En este segmento, Alsina también se encargó de destacar las hazañas heroicas de Rojas y su rol en las guerras, un hombre acostumbrado a los horrores de la violencia.

Los celos y la borrachera de Rojas son otras pruebas que indirectamente podrían haberlo señalarlo como culpable. Al igual que en los casos de pleitos anteriormente citados, Rojas habría sospechado de la infidelidad de su esposa y actuado en consecuencia, incitado además por el comprobado consumo de alcohol de ese día. Argumentaba su abogado: "pundonor es en la milicia, lavar con sangre aun los agravios mas comunes" (ibídem: 7-8). De esta forma, se entiende que la ley le permite "sacrificar dos víctimas" y que no es posible perdonar a la "enemiga" del honor (ibídem: 8). Frevert afirma que el honor era una "disposición emocional" fuertemente arraigada en la sociedad del siglo XIX (2011: s/p). Aunque la historiadora alemana se concentra en el contexto europeo, lo mismo puede decirse del americano, donde se pudo verificar que la herencia española se había trasladado a las nuevas legislaciones y modos de sociabilidad locales. El honor era importante para la vida pública de hombres y mujeres, aunque con diferentes manifestaciones que dependían también de la clase, raza, etc. Para la mujer, estaba principalmente (pero no en exclusividad) relacionado a su sexualidad y a su comportamiento sexual lo cual, una vez casada, como en el caso de Fierro, también afectaba al esposo (Frevert, 2012: $\mathrm{s} / \mathrm{p}$ ). A pesar de que existieron casos de mujeres que llevaban ellas mismas los pleitos de deshonra a la justicia, un marido (o un padre) deshonrado se veía socialmente obligado a buscar venganza por los agravios recibidos a través del accionar de sus esposas o hijas o del abuso de otro hombre sobre ellas. ${ }^{6}$ Scott Taylor, en su explicación del término dentro de la cultura española, señala sin embargo un aspecto interesante: el honor es una retórica, una performance de la ira diríamos desde una perspectiva afectiva, a la que se apela estratégicamente para esconder la imposibilidad de cumplir con los estándares morales de la sociedad (2014: 156-158). En otras palabras, el honor no solo impone cómo comportarse sino también, en su reverso, exhibe que dichas normas de comportamiento no se corresponden con la realidad de los individuos. Visto desde esta perspectiva, el honor que reclamaría Rojas al asesinar a su esposa no es más que una máscara que encubre las formas en las que se llevaban a cabo las relaciones sociales, maritales, sexuales en la época, no siempre ajustadas a la legalidad de las instituciones ni a los códigos sociales que exigían "decoro".

Otro aspecto vinculado a los afectos que trajo a colación Alsina para luego refutarlo en su defensa es el de la rareza del suicidio en países jóvenes como la Argentina. Haciendo una lectura sociológica de la naturaleza de los pueblos, el abogado defensor asoció el suicidio a los países con más historia y a los indígenas de las regiones septentrionales, donde el factor climático incidía en el suicidio, lo que no sucedería en territorios con clima más "feliz" (Belgrano, 1831: 8). Mencionó que no se conocían casos de suicidios de mujeres, ya que ellas "saben instintivamente endulzar los pesares de la vida y derramarlos del corazón con sus fáciles lágrimas" (ibídem: 8). Paralelamente, hizo

6 En La historia argentina contada por mujeres, Gabriela Margall y Gilda Manso (2018) incluyen varios ejemplos de juicios y denuncias de mujeres por maltratos, desde la época colonial hasta comienzos del siglo XX. En Hijas de la patria..., Florencia Elgorreada también incorpora historias de femicidios aparecidos en la sección “policiales” del periódico La Gazeta de Buenos Aires (2019: 33-49). 
referencia a las excepciones y mencionó a las mujeres "monstruos" que habían matado a sus esposos, es decir, mujeres que habían dejado liberada su ira y habían roto con el precepto de la mesura y la sumisión. ${ }^{7}$

Una mujer asesina transgredía los atributos considerados innatos a su género y, de esta manera, se convertía en un cuerpo indeseado, monstruoso, en tanto que desafiaba el orden patriarcal y amenazaba el ideal romántico del hogar como refugio para el hombre. Partiendo de esta lógica, Alsina diría más tarde que Encarnación Fierro sería la primera adúltera que preferiría quitarse su propia vida antes que matar a su marido. De esta manera, la teoría del suicidio femenino se formulaba como otro caso más de la incapacidad de la mujer para decidir libremente. No pudiendo deshacerse de su esposo por el peso de la ley ni pudiendo continuar la relación con su amante, la única opción de Fierro - aunque extraña para la estadística nacional- era acabar con su propia vida.

La idea del suicidio aquí aparece también ligada al amor romántico. La literatura del siglo XIX se encargó de reforzar la imagen de mujeres que se suicidaban por amor -Anna Karenina y Emma Bovary tal vez sean los ejemplos más notorios-y ha transmitido la idea de que la destrucción de sí mismas venía siempre vinculada con una enfermedad: "el mal de amores" (Higonnet, 1985: 106). El testimonio de Paulino Rojas, que escribió de "puño y letra", recaía en este argumento emocional para dar su versión de lo acontecido ese 16 de julio de 1830. Ese día, dijo Rojas (Alsina leyó en el juicio el texto en primera persona), Encarnación le pidió caña para beber y "se le notaba una especie de inquietud en el semblante" (Belgrano, 1831:11). Luego del almuerzo, en el que la esposa había permanecido en silencio, Fierro se retiró al cuarto matrimonial para llorar. Rojas describió la escena de la siguiente manera:

Entonces le dije - ¿Es posible, Encarnacion, que hasta en estos momentos, en que estás para marchar á tu casa, y al lado de tus parientes y conocidos, me dés todavía que sentir, yllores por una pasión criminal, que tanto te ha deshonrado?... Yo insistí en lo mismo; diciéndola que no llorase: que pronto tendría toda la libertad que pudiese desear; pues que le había ofrecido de un modo irrevocable que me iba á separar de ella, en llegando á Buenos Aires: pero que, entretanto esto se verificase, yo tenía derecho á aconsejarla y reprenderla siempre que tuviese porque hacerlo. (ibídem: 12)

Teniendo en cuenta el contexto anteriormente analizado sobre el modo en que las emociones de hombres y mujeres eran entendidas y el valor que el honor tenía para ambos géneros tanto en lo social como en lo legal, resulta llamativa - sino inverosímil- la postura adoptada por Rojas. Tenemos aquí a un esposo comprensivo ante el adulterio femenino, que ha prometido, en detrimento de su propia reputación, actuar en favor de los deseos extramaritales de su esposa, esos mismos que Rojas dice habían dañado el honor de la mujer (no el propio, al parecer). Todas estas promesas de libertad para Encarnación, sin embargo, se encontraban sujetas a una condición: mientras estuvieran juntxs sería él quien aplicara consejos y castigos cuando lo determinara necesario y era el marido también quien podía dar la libertad a la mujer. Rojas se convertía, en el marco del hogar, en el juez que aplicaba compasión ante las lágrimas de Encarnación y decidía sobre su futuro. Alsina, confirmando el accionar de un esposo que cumplía con su deber, sostuvo que, ante el adulterio, el militar solo había tenido "leves quejas de celos" y ejercido su "autoridad de marido" (ibídem: 20).

La reprimenda de Rojas señalando en la mujer el honor que había perdido tenía como intención final que Encarnación experimentara otra de las emociones centrales en la

7 El lema latino Notum que furens quid femina possit (sepa de qué es capaz una mujer furiosa) - presente en La Eneida y encarnado por la figura de Medea - funciona como antecedente a estas representaciones de los peligros mayores que implican la venganza o la ira cuando son expresados por el género femenino. 
construcción de la feminidad decimonónica: la vergüenza. Nussbaum en Hiding From Humanity hace referencia a esta emoción en la estructura legal como castigo y marginalización del más débil. Hacer sentir vergüenza sería una forma de expresar el disgusto - que Nussbaum rechaza por ser un sentimiento injusto y arbitrario - de una sociedad con respecto a quien se sale de la norma que esta misma establece y regula (Nussbaum, 2006; Camps, 2011). La filósofa la denomina una "vergüenza primitiva" (2006: 70), y consiste en la conciencia de un individuo de saberse fuera del estado supuestamente ideal de la mayoría, un rasgo que podría definir toda la educación de la mujer a lo largo de la historia. Pero lejos de sentir vergüenza, Encarnación, en la versión de Rojas, se llenó de furia y, antes de suicidarse producto de esas mismas "pasiones encendidas", defendió su adulterio como la norma que el supuesto código de honor esconde, según la definición de Scott ofrecida anteriormente: "no soy yo la primera mujer que ha sido infiel a su marido; $\mathrm{y}$, mientras tenga aliento, lo haré con quien sea de mi gusto, y vos no me lo privarás de ningún modo" (Belgrano, 1831:12).

En su estudio del matrimonio en la Argentina, Arnoldo Canclini incluye la historia de Rojas y Fierro y corrobora el adulterio como motivo del conflicto matrimonial, aunque el autor reafirma la versión del femicidio. ${ }^{8}$ Sostiene que Encarnación Fierro mantenía una relación, desde su llegada a Bahía Blanca, con un joven militar asistente de su marido. Debido a esto, confirma también que el matrimonio se encontraba ya separado y que tanto la relación como la separación eran de público conocimiento (2005: 157). Para ambas versiones, el factor determinante del final de Encarnación es el traslado de la pareja a Buenos Aires y la imposibilidad de Fierro de continuar con su nueva relación. Pese a ser una de las voces más contundentes en favor de los derechos de la mujer durante la primera mitad del siglo XIX, la escritora Juana Manso, al relatar el caso, evita pronunciarse a favor de una u otra teoría. Más aun, se muestra crítica y condenatoria de la relación extramarital de Fierro, a la cual contrapone las hazañas de guerra de un héroe nacional.

En Los misterios del Plata, Manso llama a Rojas un "héroe de romance", inscribiendo su relato en la tradición sentimental de los romances nacionales. La novela sigue las premisas de la literatura de la época, dentro la llamada Generación de 1837, y funciona como panfleto contra el tirano gobierno de Juan Manuel de Rosas. También se hace eco de la "revolución sentimental" del matrimonio que tiene lugar a partir del siglo XVIII. Bolufer explica que, durante esta época y a lo largo del siglo XIX, se comienza a revalorizar el amor (romántico, paternal y maternal) dentro de las relaciones matrimoniales como un signo de "progreso" que traería una "mayor afectividad e igualdad en la familia" y que dejaría atrás un antiguo régimen que no involucraba sentimientos y presuponía un vínculo autoritario (2007: 10). Así, la novela de Manso ficcionaliza en diferentes versiones del texto algunos de los episodios históricos más relevantes del período rosista y privilegia el relato de relaciones amorosas y familiares de diversos personajes históricos, entre ellos el de la condena de Paulino Rojas. ${ }^{10} \mathrm{Al}$ referirse al matrimonio de Paulino Rojas y Encarnación Fierro, su texto cruza los ideales morales y literarios presentes en textos normativos o de ficción con un caso particular de la vida cotidiana durante el rosismo. Con algunas impresiones (como los nombres de los abogados que llevaron el caso) que hablan de la amplia circulación de la historia durante el rosismo, ${ }^{11}$ la autora presenta una lectura opuesta a las contemporáneas como la de Canclini. Para Manso, Rojas es quien padece el "mal de amores" ya que, contrariamente a la mayoría de los hombres que pierden el enamoramiento una vez casados,

8 En 188o, el caso aparece mencionado también en Causas célebres argentinas: La biblioteca popular de Buenos Aires (vols. 25-27) y la muerte de Fierro se le atribuye asimismo a Rojas (1880: 142).

9 "Nosotros no nos atrevemos a condenar ni el uno ni el otro. Son muchos los motivos que pueden influir en la desunión de dos seres que al marchar al altar solo ven las flores de los primeros días de su unión y la mágica embriaguez de la pasión." (Canclini, 2005: 73)

10 Para las historias de familia y matrimonios de Juana Manso, ver Elena Grau Lleveria (2010).

11 Manso menciona a Avellaneda en lugar de a Alsina. 
el coronel ama a su esposa (2003: 73). Sin embargo, Encarnación experimenta los sentimientos opuestos hacia su marido, desde "las primeras impulsiones de hastío" a la repugnancia que "principió a roerle el corazón” y, finalmente, al odio que "estalló como la consecuencia natural" y en el "infortunio" para la mujer: "ila infidelidad a su marido y la guerra doméstica!" (ibídem: 73).

Leído desde el presente, el relato de Manso, lejos de presentarse como un caso ejemplar de la "revolución sentimental" y la igualdad que trae consigo, demuestra más bien que la idea del amor sentimental, en palabras de Bolufer, "resulta profundamente desigual, al implicar para las mujeres una mayor exigencia afectiva y una responsabilidad más acentuada de cara al éxito de la unión" (2007: 11). Así, al recaer todo el peso emocional del matrimonio sobre la esposa, esta, con razón, articulaba toda su vida en función de llevar adelante con éxito esa unión, haciendo a un lado su propia subjetividad y sus intereses o, más aun, sin siquiera cuestionar que tales intereses individuales podían ser posibles por fuera de su vida con un hombre. Un matrimonio exitoso, en las antípodas del de Rojas y Fierro, era entendido como ingrediente esencial del orden y la felicidad públicos (Bolufer, 2007). Así también lo demostraron las páginas del primer periódico dirigido por una mujer publicado durante el primero gobierno de Rosas, La Aljaba. ${ }^{12}$ Aunque con ciertos gestos protofeministas que denuncian la marginalización de la mujer, este proyecto periodístico se inscribe en un "programa moral" (Auza, 1988: 22) que respeta los patrones de comportamiento y modestia para el género femenino. Por ejemplo, el artículo "Felicidad de las mugeres" (2004: 44) liga directamente las emociones femeninas al éxito del matrimonio. Otro artículo se refiere al lujo vinculado al rol de la mujer en la familia: el lujo y la frivolidad femeninos traen conflictos que terminan en el odio de la pareja, aunque no se especifica que lo mismo ocurra si provienen de parte del hombre, simplemente porque son prácticas naturalizadas como exclusivamente femeninas. Por otra parte, el artículo "Felicidad de las señoras" (ibídem: 31), mientras condena el maltrato de los hombres a sus esposas, exhorta a las mujeres, y no a sus maridos, a cambiar sus actitudes individuales para así modificar la conducta masculina. La revista no deja de insistir en el concepto de felicidad, al que se le oponen las ensoñaciones y deseos excesivos de la mujer como motivo de ruina matrimonial. "Pensar bien y hablar poco" es uno de los consejos del periódico para sus lectoras (ibídem: 93).

Respondiendo a este contexto, en el juicio a Rojas, Alsina refuerza su argumento del suicidio trayendo a colación modelos disponibles en el mundo de la literatura, en este caso, las palabras de Mme. de Staël: "El amor es toda la historia de la vida de una mujer; y solo un breve episodio de la del hombre" (Belgrano, 1831: 20). ${ }^{13}$ "La situación moral de Encarnación Fierro" pasa así a ser una parte fundamental de la defensa y se reflexiona sobre la "criminalidad" del amor ilícito de las mujeres (ibídem: 20). ${ }^{14}$ 12 La Aljaba apareció 18 de noviembre de 1830 en Buenos Aires. Se trató del primer periódico escrito por mujeres y editado y financiado con recursos de una mujer. La publicación fue liderada por la periodista Petrona Rosende de la Sierra, y dejó de aparecer el 18 de enero de 1831, al parecer por problemas financieros. Solo se editaron dieciocho números en la Imprenta del Estado, durante el primer gobierno de Rosas.

13 Junto con una literatura occidental que refuerza la sentimentalidad y el amor romántico como esenciales en la vida de la mujer, existe paralelamente una tradición novelística con personajes femeninos que denuncian situaciones que antes hubieran quedado en silencio y buscan por la justicia separarse de sus maridos. Encarnación Fierro puede ser parte de este fenómeno reflejado en la literatura, ya que la mujer, según los testimonios presentados, quería separarse de su marido, no quería volver a Buenos Aires porque esa sería su "muerte" en vida y tendría que vivir más restringida a los códigos de la época, que en una ciudad se imponen con más fuerza frente a otros familiares, espacios públicos e instituciones. La ausencia de todo eso en Bahía Blanca tal vez le permitió desarrollar esas ideas de vida alternativa a las que no quería renunciar. Ver The Invisible Code... (1997) de William M. Reddy para un análisis de estos casos literarios en el contexto francés.

14 Dice Alsina: "Es tan limitada la esfera, que la naturaleza, o la sociedad ha trazada á la existencia de la mujer; tan grande la distancia, que la separa del perpetuo combate de intereses y aspiraciones, en donde el hombre se halla empeñado desde la primera época de su juventud; que el amor, para el bello sexo, es el acontecimiento más importante de la vida. [...] Diversos afectos pueden asignarse como origen de las virtudes femeniles; pero la causa de sus crímenes en el orden actual de nuestras sociedades, apenas puede ser otro que el amor ilícito" (Belgrano, 1831: 20). 
Paralelamente, se apela a la moralidad y a las consecuencias negativas de la emotividad femenina para provocar compasión y con la seguridad de que el juez compartirá el universo de valores que condena el adulterio femenino, tanto para el caso de que crea que ha sido Rojas el asesino y aminore su pena, como para convencerse del suicidio de la mujer. Alsina argumenta que Fierro se había "abandonado, hacía tiempo, a todos los excesos de una ciega pasión, que, por su desgracia, le inspiró un joven huésped de su esposo" (ibídem: 20). Al sentar las bases del adulterio y establecer que este era de público conocimiento, el abogado determina: "si este golpe [el haberse enterado Rojas de la infidelidad de su esposa] hubiera sido repentino... quizás las leyes tendrían hoy que permanecer en silencio" (ibídem: 20). Es decir, la ley lo habría protegido si Rojas hubiera actuado bajo lo que se conoce en el campo legal como "emoción violenta". Con esto, aunque la labor de Alsina es convencer y conmover al juez de la inocencia de Rojas, el letrado deja igualmente en claro que en circunstancias que involucran la infidelidad femenina y el honor masculino, el castigo no debe ser aplicado con la severidad de otros homicidios. Finalmente, si el amor es todo en la vida de la mujer y Encarnación Fierro, según los testimonios reunidos de allegados, prefería morir antes que volver con su marido a Buenos Aires y alejarse de su amante, para Alsina no caben dudas de que este ha sido un suicidio premeditado. Aun así, recurre a la compasión argumentando la orfandad de la hija, que se ha quedado sin madre y se quedaría sin padre de ser condenado Rojas. Así logra revocar la pena de muerte inicial y conseguir la ya referida sentencia al exilio.

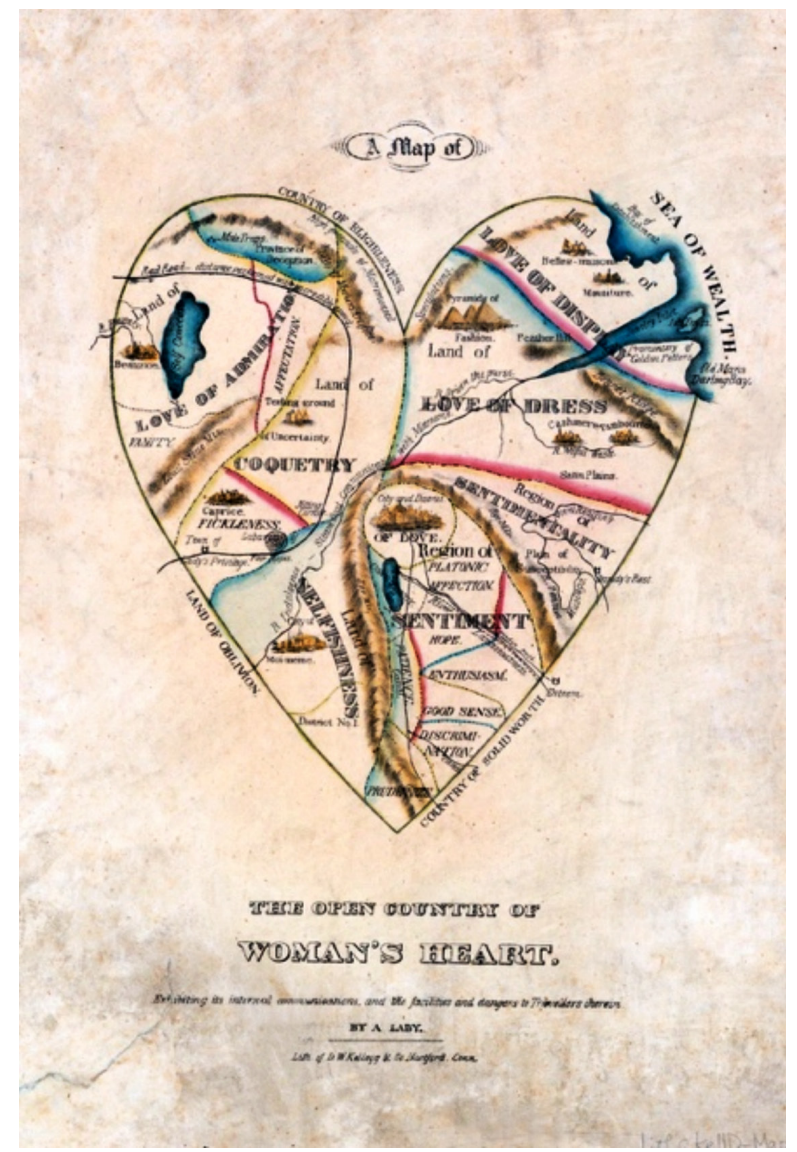

Figura 3. A Map of the Open Country of a Woman's Heart (Un mapa del país abierto del corazón de una mujer) de D. W. Kellogg, c. 1833-1842. La imagen refleja las ideas decimonónicas sobre las mujeres y sus emociones, argumentos centrales en el juicio a Paulino Rojas. Según el mapa, el amor se encuentra en el centro del corazón de las mujeres, mientras que la sección de Sentimentalidad y Sentimiento, que incluye emociones como el amor platónico, ocupan una gran porción de todo el territorio. Otras regiones en el mapa señalan, al igual que las páginas de La Aljaba, los peligros que envuelven la coquetería y la frivolidad para una mujer. 
Para finalizar, a la hora de adentrarse en las pruebas a favor de la inocencia de Rojas y a fin de constatar que la muerte de Fierro ha sido un suicidio, Alsina recurre a la medicina, un discurso y una disciplina para la cual las emociones son igualmente centrales. En primer lugar, arguye que el médico inglés que acudió a la escena del crimen no estaba autorizado por el tribunal de medicina argentino, por lo tanto, sus conclusiones sobre el homicidio de Fierro no deberían ser tomadas en cuenta. El abogado también cuestiona los modos de "leer" la anatomía del cadáver de Fierro desde signos de emotividad erróneos: mientras que el médico sostiene que Encarnación fue encontrada con las manos en posición de súplica y que, consecuentemente, ha sido asesinada, para Alsina las manos entrelazadas son un signo de "cólera, amenaza o despecho" (ibídem: 18). Así, el juicio se construye no solo alrededor de las emociones de las víctimas y victimarios, sino que depende también de cómo las interpretan terceros, incluyendo un nivel subjetivo que se repone también culturalmente.

En el documento judicial, la referencia médica más interesante es tal vez el argumento de la "predisposición constitucional hereditaria": Encarnación Fierro es hija de una madre depresiva y, por lo tanto, ella también lo es. Su organismo naturalmente "exalta o debilita la sensibilidad" innata de su género (ibídem: 24), dirá la defensa de Rojas. En el juicio se certifica que, aunque la madre de Fierro no era suicida sino histérica, esta condición había predispuesto a su hija a la melancolía y habitual desazón que Fierro ha absorbido "desde el vientre materno" y que se ha vuelto "germen fatal del descontento de la vida" (ibídem: 25). Al revisar los tratados y debates médicos del siglo XIX, se puede concluir que los argumentos en defensa de Rojas se sostienen en teorías de la época tales como las del norteamericano Benjamin Rush y su noción de "insanidad moral". En Medical Inquiries and Observations upon Diseases of the Mind (1812), Rush aseveraba - con nociones similares a las de los humores ya vistas-que las enfermedades mentales eran causadas por irritaciones en los vasos sanguíneos del cerebro y proponía como cura la purga, el sangrado y los baños fríos y calientes. ${ }^{15}$ Estas teorías que combinaban pensamientos morales con científicos se basaron también en el presupuesto de una desigualdad biológica de la mujer, argumento evolucionista de la disposición "natural" del género femenino a un permanente estado nervioso. Esta suposición de la mujer nerviosa "fue convenientemente utilizada en el desarrollo de los juicios de divorcio por parte de sus esposos y los representantes judiciales de estos" y, como vemos en el caso de Fierro, como línea argumental de la defensa en casos de homicidio (Undurraga Schüler, 2016: 408).

Al hacer referencia a la enfermedad transmitida por vía materna, Alsina adopta otras teorías médicas que se importaron de Europa y se adaptaron al contexto nacional años más tarde como, por ejemplo, las del médico argentino Guillermo Rawson, quien se recibiría en 1844 con una tesis que estudiaba la transmisión de las facultades fisiológicas y patológicas por vía de la herencia. El tema de la herencia, explica Mariano Di Pasquale, "era una de las incógnitas más importantes de la época" a pesar de que en países como Francia se consideraban ya pasadas de moda (2019: 742 ). ${ }^{16}$ El galeno sostenía que las enfermedades y los "estados morales" de los padres se trasladaban a los hijos en las etapas que también señala Alsina para hablar de Encarnación: cuando empieza la existencia orgánica del "germen", durante la gestación y la lactancia (Di Pasquale, 2019: 743). Pablo Ben sostiene también que, durante el siglo XIX, la medicina ocupaba (como en el siglo siguiente) un lugar destacado dentro del Estado a la hora de establecer las normas y anomalías de los cuerpos masculinos y femeninos (2000: 253). Sobre las mujeres y en relación con su piscología, el historiador explica que la psiquis se consideraba una manifestación de la materia (el cuerpo). La maternidad, por ejemplo, surgía como una de las actividades más propicias para el cerebro de la

15 Sobre el uso de la moral en las teorías de Rush, ver Carlson y Simpson (1965: 22-23).

16 Ver también el artículo de Di Pasquale (2019: 733-752) para un panorama más completo sobre el estado de la medicina durante el rosismo. 
mujer, para evitar la aparición de síntomas pensados como exclusivamente femeninos: la ya mencionada "sensibilidad extremada", la imaginación muy viva - esa que había despertado las ensoñaciones románticas de Fierro-, y los juicios abruptos producto de esas mismas emociones y no de la razón -el suicidio de Fierro, en este caso (Ben, 2000: 254). No es casualidad que el descuido y desinterés de Fierro por su hija se mencionen como manifestaciones de la "enfermedad" de la mujer: "Poseída como se hallaba esta infeliz joven de tan frenética pasión; qué atractivo podría presentarle la vida? [...] ¿Su hija...? ¿Podría ser madre la que había dejado de ser esposa?... La soledad, por otra parte, de aquel lugar desierto, en donde moraba, nada le ofrecía que pudiera distraerla de sí misma" (Belgrano, 1831: 21).

De esta manera, la falta de indicios directos, de pruebas que certificaran que efectivamente Paulino Rojas había asesinado a su esposa, sumada a la proliferación de argumentos legales, médicos y preceptos culturales que ponían siempre y en primer lugar bajo sospecha el comportamiento de la mujer, hicieron del juicio presentado, un claro ejemplo del dominio masculino sobre la ley y la conformación del Estado en el siglo XIX rosista. Tal como lo presenta su abogado, el instante en el que ocurre la muerte de Fierro no se pueden imponer sobre "17 años de honor y heroísmo" de Paulino Rojas (30). Y efectivamente no lo hacen. Paradójicamente, cuatro años después de la exoneración de la pena por parte de Rosas, Rojas fue condenado a muerte por conspiración contra el Restaurador y fusilado en Buenos Aires el 29 de mayo de $1835 .{ }^{17}$

\section{Conclusiones}

Nussbaum brinda algunas claves para reflexionar sobre la importancia de leer la ley desde las emociones y las emociones desde el plano legal. La filósofa establece que apelar a las emociones es un acto prominente para la legislación de cualquier período y, consecuentemente, esto comprueba que cuando hablamos de una sociedad desde lo emocional, no estamos hablando de fuerzas instintivas sino todo lo contrario (2006: 21-22). Las emociones se forman culturalmente y justifican o determinan los contornos de la ley y cómo debemos sentirnos ante actos como el homicidio: miedo, enojo, compasión. Concluye Nussbaum "La ley en este sentido contiene un modelo de lo que provoca a una persona razonable hacia emociones extremas y lo que no" (2006: 40, mi traducción).

Esta misma funcionalidad de las emociones se pudo leer en el caso de Paulino Rojas y la muerte de Encarnación Fierro, ya que los argumentos legales y médicos alrededor de la sensibilidad excesiva de la mujer frente al control racional del hombre se presentan como argumentos para impedir la clara caratulación y condena del hecho como homicidio. Pudimos observar también que, durante el rosismo - período al que la literatura y cultura argentinas aun hoy continúan haciendo referencia para sentar las bases de o cuestionar la identidad nacional- se establece un orden en el que lo normativo y disciplinario recae con más fuerza sobre la mujer y sobre otros cuerpos racializados y/o marginalizados que se vuelven cuerpos "sin respaldo legal" (Leonardi, s/f: 8). A pesar de la ruptura con la metrópolis tras la independencia, la sociedad en tiempos de Rosas sigue sosteniendo el honor como el valor más preciado en todos los sectores, pero más aún si se trata de "héroes" de dicha gesta independentista. Así, aunque se trate de un período en el que se condena duramente todo lo que está fuera de la norma rosista, esa norma también se ajusta - con parámetros que generalmente recurren a una emocionalidad colectiva- de acuerdo con la identidad de víctimas y victimarios. Las emociones funcionan aquí como construcciones que

17 José Rivera Indarte incluye el fusilamiento de Paulino Rojas en su libro Efemérides de los degüellos, asesinatos y matanzas del degollador Juan Manuel de Rosas (s/f: 13). 
justifican el descarte y desvalorización de los cuerpos femeninos como el de Fierro, por ser estos enfermos, irracionales, sensiblemente descontrolados. Aunque no ha sido el enfoque de este trabajo, todas las referencias al control/descontrol emocional de la mujer remiten también a los intentos de reprimir la sexualidad y el erotismo femeninos. Reconociendo la vigencia de estos discursos en el presente, el acto de revisar el archivo y trazar el origen emocional de la ley en un período o región en particular (la Argentina rosista en este caso) permite desmontar la maquinaria letrada femicida que sigue cobrándose cuerpos día a día, pese a las modificaciones de la ley. ${ }^{18}$
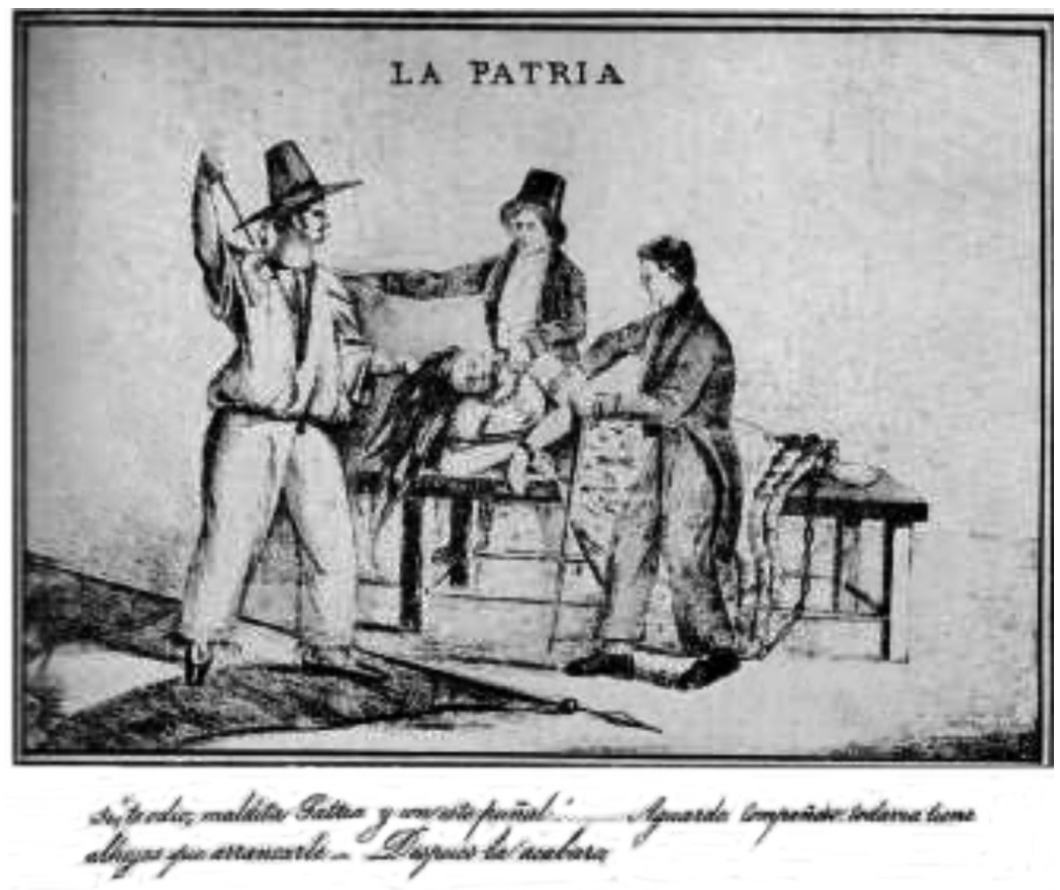

Figura 4. La patria, ilustración de El Grito Argentino, núm. 1, Montevideo, 24 de febrero de 1839. Rosas es representado como cuchillero o matarife que atenta contra el cuerpo feminizado de la nación.

18 En 2012, la Cámara de Diputados de la Argentina aprobó por unanimidad una ley por la que se agravó la pena por homicidio de una mujer o una persona transexual cuando se determine que el crimen estuvo motivado por el género. 


\section{Dibliografía}

"AA.VV. (1880). Causas célebres argentinas: La biblioteca popular de Buenos Aires (vols. 25-27). Buenos Aires, La biblioteca popular de Buenos Aires.

» Anónimo. El uxoricidio de la esposa de un coronel. En La gaceta mercantil. En línea en: https://www.gacetamercantil.com/notas/154715/el-uxoricidio-de-laesposa-de-un-coronel.html

"Ahmed, S. (2015). The Cultural Politics of Emotion. Abigdon, Routledge.

»Barclay, K. (2017). Narrative, Law and Emotion: Husband Killers in Early Nineteenth-Century Ireland. En The Journal of Legal History, vol. 38, núm. 2.

"Barrancos, D. (2010). Mujeres en la sociedad argentina. Una historia de cinco siglos. Buenos Aires, Sudamericana.

»Belgrano, M. (1831). Informe sobre la causa criminal seguida de oficio contra el Coronel D. Paulino Rojas por sospechársele homicida de su esposa Doña Encarnación Fierro. Buenos Aires, Imprenta Argentina.

"Ben, P. (2000). Cuerpos femeninos y cuerpos abyectos. La construcción anatómica de la feminidad en la medicina argentina. En Historia de las mujeres en la Argentina, tomo I, Colonia y siglo XIX. Buenos Aires, Fernanda Gil Lozano,/ Taurus-Santillana.

"Berlant, L. (2011). El corazón de la nación. Ensayos sobre política y sentimentalismo. México DF, FCE.

»Bolaños Florido, L. P. (2016). El estudio socio-histórico de las emociones y los sentimientos en las Ciencias Sociales del siglo XX. En Revista de Estudios Sociales, núm. 55, enero-marzo. En línea en: https://journals.openedition.org/ revestudsoc/9762

"Bolufer, M. (2007). "Hombres de bien": modelos de masculinidad y expectativas femeninas, entre la ficción y la realidad. En Cuadernos de llustración y Romanticismo, núm. 15.

"----. (2009). Medicine and the Querelle des Femmes in Early Modern Spain. En Medical history. Supplement, núm 29. pp. 86-106.

》Bucich Escobar, I. (s/f). Tragedias de nuestra historia.

»Buompadre, J. (2013). Los delitos de género en la reforma penal (Ley no 26.791). En línea: http://www.pensamientopenal.com.ar/system/files/2013/o2/doctrina35445.pdf

»Canclini, A. (2005). Sí, quiero: historias y anécdotas del matrimonio en la Argentina (siglos XVI a XIX). Buenos Aires, Emecé.

"Camps, V. (2011). El gobierno de las emociones. Barcelona, Herder.

»Carlson, E. T. y Simpson, M. M. (1965). Benjamin Rush's Medical Use of the Moral Faculty. En Bulletin of the History of Medicine, vol. 39, núm. 1.

"Carmona, J. I. y Fernández, C. E. (1999). El derecho penal en tiempo de Rosas. Un análisis a partir de la obra de Esteban Echeverría. Trabajo presentado en la clase de Elementos de Derecho Penal y Procesal Penal, cátedra Dr. Hendler, Adjunto Tedesco, primer cuatrimestre. En línea en: http://www.derecho.uba. $\mathrm{ar} /$ publicaciones/lye/revistas/75/el-derecho-penal-en-tiempos-de-rosas-un- 
analisis-a-partir-de-la-obra-de-esteban-echeverria.pdf

"Clough, P. y Halley, J. (2007). The Affective Turn: Theorizing the Social. Durham, Duke University Press.

»De Angelis, P. (s/f). Recopilación de las leyes y decretos promulgados en Buenos Aires, desde el 25 de mayo de 1810, hasta fin de diciembre de 1840.

»Di Pasquale, Mariano,M. (2019). "Saberes médicos y reflexiones morales durante el período rosista: Buenos Aires, 1835-1847. En 囚,História, Ciências, Saúde $\triangle$ Manguinhos, Rio de Janeiro, vol. 26, núm. 3, julio-septiembre, julio-septiembre 2019.

"Elgorreaga, F. (2019). Hijas de la patria. Mujeres, ideología y política en la literatura argentina (1810-1860). Buenos Aires, Tren en movimiento.

»Elias, N. (1978). The civilizing Process. Oxford, Basil Blackwell.

» Fernández, A. M. (2012). Femicidios: La ferocidad del patriarcado. En Revista Nomadías, núm. 16, noviembre.

» Fernández Rozas, J. C. (2005). El Código de Napoleón y su influencia en América Latina: reflexiones a propósito del Segundo Centenario. En El derecho internacional en tiempos de globalización: libro homenaje a Carlos Febres Pobeda. Mérida, Universidad de los Andes, Publicaciones del Vicerrectorado Académico.

» Frevert, U. (2011). Emotions in History. Lost and Found. Central European University Press. En línea en: https://books.openedition.org/ceup/1496

» Gilligan, C. (1993). In a Different Voice: Psychological Theory and Women's Development. Cambridge, Harvard University Press.

» Grau-Lleveria, E. (2010). La ficción política romántica en Los misterios del Plata. Episodios de la época de Rosas, escritos en 1846 de Juana Paula Manso. En Decimonónica, vol. 7, núm. 1, invierno, pp. 1-20, En línea en: http://www.decimononica.org/la-ficcion-politica-romantica-en-los-misterios-del-plata-episodiosde-la-epoca-de-rosas-escritos-en-1846-de-juana-paula-manso/

» Higonnet, M. (1985). Suicide: Representations of the Feminine in the Nineteenth Century. En Poetics Today, vol. 6, núm. 1/2.

»Isaac, J. (1864-1867). María.

» La Aljaba. Dedicada al bello sexo argentino. 1830-1831. (2004). Auza, N. T. (ed.). Buenos Aires, El archivo.

"Leonardi, R. (s/f). Los cuerpos lacerados: iconografía y archivos judiciales. Buenos Aires 1830-1852. En línea en: https://catedraleonardi.com.ar/ v2/?portfolio=los-cuerpos-lacerados-iconografia-y-archivos-judiciales-buenos-aires-1830-1852

»Levaggi, A. (2012). El derecho penal argentino en la historia. Buenos Aires, Facultad de Derecho/EUDEBA.

» Macón, C. (2014). Género, afectos y política. Lauren Berlant y la irrupción de un dilema. En Debate Feminista, vol. 49, abril, pp. 163-86.

» Manso de Noronha, J. (2010 [1854]). La emancipación moral de la mujer. En línea en: http://juanamans01819.blogspot.com/2010/o6/emancipacion-de-lamujer.html

»----. (2003 [1846]). Los misterios del Plata, Biblioteca Virtual Universal. En línea en: https://www.biblioteca.org.ar/libros/71176.pdf 
»Margall, G. y Manso, G. (2018). La historia argentina contada por mujeres. Buenos Aires, Penguin Random House.

》 Mármol, J. (1851-1852/1855). Amalia.

» Matto de Turner, C. (1889). Aves sin nido.

» Mira, J. (2018). La tensión entre sistema penal y derecho penal. El caso de la impartición de justicia y las penas capitales durante el gobierno de Juan Manuel de Rosas en tiempos de la Confederación Argentina (1829-1852). En Lex Social, vol. 8, núm. 1 .

» Mosso, C. J. (2017). El caso Paulino Rojas. En Revista Cruz de Sur, vol. VII, núm. 22.

" Mouffe, C. (2009). The Democratic Paradox. Londres, Verso.

» Nussbaum, M. (2006). Hiding from Humanity. Nueva Jersey, Princeton University Press.

" Olaza Pallero, S. (2016). Un aspecto del sistema judicial rosista: los juzgados de paz de campaña en la Provincia de Buenos Aires. En AEQUITAS virtual. Publicación de la facultad de ciencias jurídicas, vol. 10, núm. 26. En línea en: https://p3.usal.edu.ar/index.php/aequitasvirtual/article/view/4232

»Peluffo, A. (2005). Lágrinas andinas: sentimentalismo, género y virtud republicana en Clorinda Matto de Turner. Pittsburgh, Instituto Internacional de Literatura Iberoamericana.

»----. (2016). En clave emocional: cultura y afecto en América Latina. Buenos Aires, Prometeo.

»Reddy, W. (1997). The Invisible Code: Honor and Sentiment in Postrevolutionary France, 1814-1848. Berkeley, University of California Press.

》Registro Oficial del Gobierno de Buenos Aires (1831). Libro décimo. Buenos Aires, Imprenta de la Independencia.

"Rousseau. J.-J. (1761). Julia, o la nueva Eloísa.

»-----. (1763). Emilio, o de la educación.

»Rivera Indarte, J. (s/f). Efemérides de los degüellos, asesinatos y matanzas del degollador Juan Manuel Rosas. Imprenta del Nacional.

»Rush, B. (1812). Medical Inquiries and Observations upon Diseases of the Mind.

"Salvatore, R. (1994). El Imperio de la Ley. Delito, Estado y Sociedad en la era Rosista. En Delito y Sociedad. Revista de ciencias Sociales, vol. 3, núm. 4-5.

» Taylor, S. (2014). "Honor", Lexikon of the Hispanic Baroque Transatlantic Exchange and Transformation. Levy, E. y Mills, K. (eds.). Texas, University of Texas Press.

»Undurraga Schüler, V. (2016). De coléricas a nerviosas. Emociones femeninas y sus ejes de comprensión. Chile, 1840-189o. En Las mujeres y las emociones en Europa y América. Siglos XVII-XIX. Candau Chacón, M. L. (ed.). CIUDAD, Editorial Universidad Cantabria.

»Weber, M. (1993). Economía y sociedad: Esbozo de sociología comprensiva, vol. 1, Winckelmann, J. (ed.). Mexico DF, FCE.

»Williams, R. (1977). Marxism and Literature. Oxford, Oxford University Press.

"Zemon Davis, N. (1987). Fiction in the Archives: Pardon Tales and Their Tellers in Sixteenth-century France. Palo Alto, Stanford University Press. 
